\title{
Expression of Ethylene Response Factor Genes during Fresh-cut Lotus Root Storage and Browning
}

\author{
Ting Min, Jun Xie, Yang Yi, Wenfu Hou, Youwei Ai, and Hongxun Wang ${ }^{1}$ \\ College of Food Science \& Engineering, Wuhan Polytechnic University, Wuhan, 430023, People's \\ Republic of China
}

\begin{abstract}
AdDitional Index words. Nelumbo nucifera, gene expression, PAL, PPO, POD, ERF
Abstract. Ethylene response factor $(E R F)$ genes have been characterized in numerous plants in which they are involved in responses to biotic and abiotic stress, including cold and heat stress. Cool temperatures is one of the most effective storage methods for delaying browning of fresh-cut lotus (Nelumbo nucifera) root. In model plants, ERF genes have been identified as being responsive to cold and heat stress. Whether $E R F$ is associated with lotus root browning in cooler temperatures has not been studied. In this research, low-temperature storage $\left(4^{\circ} \mathrm{C}\right)$ effectively delayed browning of fresh-cut lotus root. Using RNA sequencing, seven Nelumbo nucifera ERF (NnERF) genes were isolated and studied. Transcriptional analysis indicated $N n E R F$ genes responded differently to temperature. $N n E R F 3 / 4 / 5$ were reduced continuously by a low temperature $\left(4^{\circ} \mathrm{C}\right)$ and $N n E R F 5$ was the most strongly downregulated. In contrast, transcripts of $N n E R F 1 / 2 / 7$ were increased at a low temperature $\left(4^{\circ} \mathrm{C}\right)$. The expression of $N n E R F 6$ showed no obvious difference between the two different temperatures. It is proposed that $N n E R F 3 / 4 / 5$ could be important candidates as regulators of fresh-cut lotus root browning. The roles of other members are also discussed.
\end{abstract}

$E R F$ genes encode plant-specific transcription factors that are located downstream of the ethylene signaling pathway (Nakano et al., 2006). ERFs are members of one of the largest transcription factor families, which is considered a superfamily, and is involved in plant biological and abiotic stress responses (Licausi et al., 2013; Min et al., 2012; Müller and MunnéBosch, 2015; Phukan et al., 2017). It has been reported that CsAP2/ERF(APETALA2/ERF) may play important roles in the abnormal temperature stress response in Camellia sinensis $(\mathrm{Wu}$ et al., 2015). TERF2/LeERF2 enhance the freezing tolerance of Nicotiana tabacum and Solanum lycopersicum through ethylene biosynthesis and the ethylene signaling pathway (Zhang and Huang, 2010). NnDREB2 (dehydration response element binding)/ERF might play an important role in the salt stress adaptation of plants by binding directly with the dehydration responsive element, regulating downstream gene expression in salt-resistant lotus (Cheng et al., 2015a). In fruits and vegetables, $E R F$ genes are key targets for investigating the transcriptional regulatory roles in fruit and vegetable development and ripening (Karlova et al., 2011; Licausi et al., 2013; Mizoi et al., 2012; Xu et al., 2011).

Fresh-cut lotus root slices have received increasing attention because they are extremely convenient and highly edible (He et al., 2017; Sun et al., 2015; Zhang et al., 2013). However, it is well known that enzymatic browning is the most serious problem for fresh-cut lotus root during processing and storage, limiting the shelf life of lotus root slices (Conesa et al., 2007; Francis et al., 2012; Hodges and Toivonen, 2008). Phenylalanine ammonia lyase (PAL), polyphenol oxidase (PPO), and peroxidase (POD) have been reported previously as being involved in enzymatic browning of many species (Banerjee

Received for publication 19 July 2018. Accepted for publication 26 Sept. 2018. This research was supported by National Key Research and Development Program of China (no. 2016YFD0400100) and Research Institute of Wuhan Polytechnic University (2018J02).

${ }^{1}$ Corresponding author. E-mail: 496662875@qq.com. et al., 2015; Cheng et al., 2015b; Zheng et al., 2016; Zhou et al., 2003). Our previous research reported that $N n P A L 1, N n P P O A$, and NnPOD1-6 are the most important candidate genes for the browning of fresh-cut lotus root (cv. E Lian 6) during storage at different temperatures (Min et al., 2017). However, many aspects of transcriptional regulation in lotus root senescence and quality are yet to be explored.

It has been reported that 1-methylcyclopropene (an ethylene inhibitor) treatment reduced rachis browning, whereas ethylene tended to enhance it in Vitis vinifera(Li et al., 2015). Ethylene can increase the activity of phenolase in fresh-cut Colocasia esculenta and accelerate the occurrence of browning during storage (Tan and Zeng, 2014). It is well known that the biological function of ethylene is realized through the ethylene signal transduction pathway. As the most important element in the ethylene signal transduction pathway, ERF plays an important role in the realization of ethylene function (Nakano et al., 2006). It has been reported that DcERF1 and DcERF2 may function in different ways in committing to the upregulation of DCPAL3 promoter activity in anthocyanin-synthesizing Daucus carota cells (Kimura et al., 2008). In addition, carbon dioxide has been shown to downregulate expression of $E R F$ genes in Medicago truncatula infested by Acyrthosiphon pisum and to reduce resistance against $A$. pisum in terms of less POD and PPO activity (Guo et al., 2014). This suggests that $E R F$ may be involved in the synthesis of phenolic precursors through the transcriptional regulation of $P A L$ in plants, or the transcriptional regulation of $P P O$ and $P O D$ involved in plant stress responses. However, there is a lack of experimental evidence for this in relation to lotus root.

In this research, seven of $38 \mathrm{NnERF}$ genes were isolated from lotus root based on differentially expressed genes in an RNA sequencing (RNA-Seq) database and the National Center for Biotechnology Information (NCBI) database (Supplemental Table 1). In the treatment, lotus root was stored at 4 and $20{ }^{\circ} \mathrm{C}$, and $N n E R F$ transcripts were analyzed throughout the browning process. Some $N n E R F$ genes were found to correlate positively 
with lotus root browning. The possible roles of these and other $N n E R F$ genes are discussed.

\section{Materials and Treatments}

Lotus roots ('E Lian 5') were sourced from a commercial agricultural wholesale market (Si Ji Mei Agricultural Wholesale Market, Wuhan, China) in 2016 and then transported to the laboratory. The batch and treatment of 'E Lian 5' lotus roots were the same as that used in our previous report (Min et al., 2017). Before treatment, the lotus roots were stored at $4{ }^{\circ} \mathrm{C}$ for $24 \mathrm{~h}$. They were washed with tap water to remove soil and were peeled. They were then cut into 5-mm-thick slices along the cross-section of the lotus root. After being transferred to clean water, and soaked for $2 \mathrm{~min}$, these fresh-cut lotus root slices were dried with filter paper and packed in fruit and vegetable boxes $(18.8 \times 12 \times 1.5 \mathrm{~cm})(\mathrm{MS}-08$; SUNWAY KORDIS, Shanghai, China), with two pieces in each box, and transferred to the refrigerator $\left(4\right.$ and $20^{\circ} \mathrm{C}$, respectively).

BROWNING DEGREE. The extraction and determination of degree of browning were carried out according to our previous report (Min et al., 2017). Flesh tissue (3.0 g) was homogenized with $30 \mathrm{~mL}$ distilled water at $4{ }^{\circ} \mathrm{C}$, then centrifuged at $10,000 g_{\text {n }}$ for $5 \mathrm{~min}$ at $4{ }^{\circ} \mathrm{C}$. The supernatant was collected and incubated in a $25{ }^{\circ} \mathrm{C}$ water bath for $5 \mathrm{~min}$. Absorbance was measured using a spectrophotometer (GL-20G-II; Shanghai Anting, Shanghai, China) at $410 \mathrm{~nm}$; browning degree (BD) was expressed as A410 $\times 10$.

Total PhenOlic content. Total phenolic content was measured according to our previous article (Min et al., 2017). A 3.0-g fresh sample of flesh tissue was homogenized with 30 $\mathrm{mL} 60 \%$ ethanol and centrifuged. The results are expressed as milligrams gallic acid equivalents per kilogram fresh weight, and all treatments were performed with three biological replicates.

PAL ACTIVITy. The extraction and assay of PAL activity were performed using a phenylalnine ammonia-lyase kit (Nanjing Jiancheng Bioengineering Institute, Nanjing, China), as described previously (Min et al., 2017). Flesh tissue (0.1 g) was homogenized in $1 \mathrm{~mL}$ extracting solution in an iced mortar, and the solution was then centrifuged at $10,000 \mathrm{~g}_{\mathrm{n}}$ for $10 \mathrm{~min}$ at $4{ }^{\circ} \mathrm{C}$. The supernatant was collected as a crude PAL extract. The reaction mixture consisted of $20 \mu \mathrm{L}$ crude PAL extract, $780 \mu \mathrm{L}$ reagent 1 (the blank group for $800 \mu \mathrm{L}$ ) and $200 \mu \mathrm{L}$ reagent 2 . Afterward, the mixture was incubated at $30{ }^{\circ} \mathrm{C}$ for $30 \mathrm{~min}$, and $40 \mu \mathrm{L}$ reagent 3 was added into the previous mixture and was left to stand for $10 \mathrm{~min}$. The absorbance value of the sample at $290 \mathrm{~nm}$ was measured. Enzyme activity units (U) were defined spectrophotometrically as a change of 0.1 in absorbance per minute per gram fresh weight.

PPO ACTIVITY. The extraction and assay of PPO activity were performed as described previously (Min et al., 2017). Flesh tissue $(3.0 \mathrm{~g})$ was homogenized in $50 \mathrm{~mL}$ phosphate-buffered

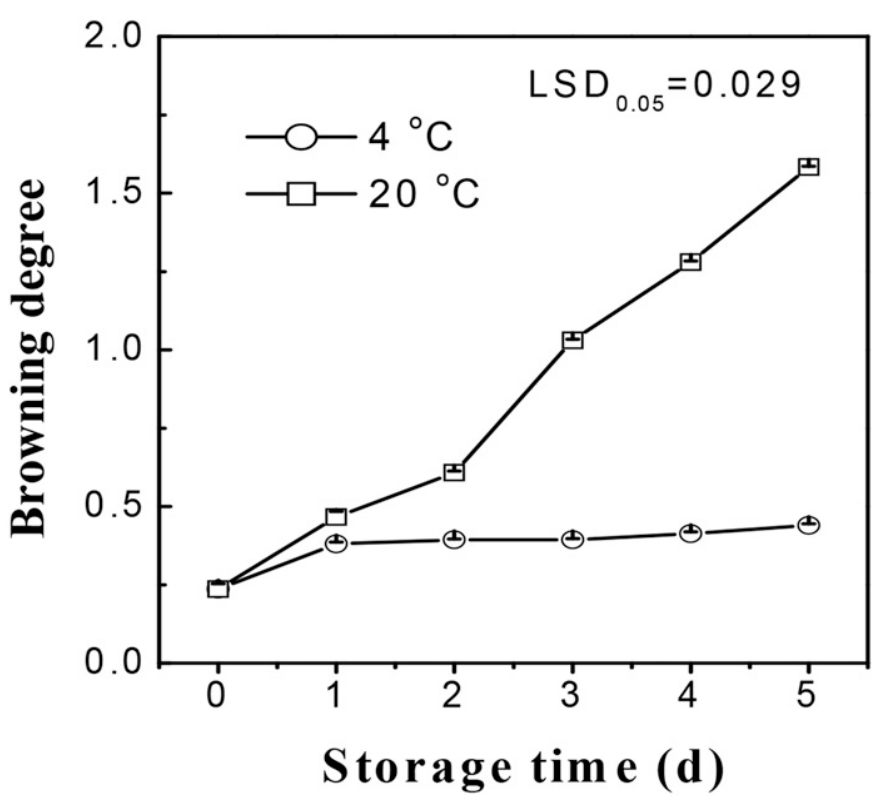

Fig. 1. Effects of two different temperatures on browning degree of fresh-cut lotus root ('E Lian 5'). Browning degree was chosen as the main index of browning, with more serious browning indicated by greater index values. Fresh-cut lotus root was stored at $4{ }^{\circ} \mathrm{C}$ (circles) and $20^{\circ} \mathrm{C}$ (squares), separately. Error bars represent the SE from three biological replicates. LSD = least significant difference.

saline (PBS; $0.05 \mathrm{~mol} \cdot \mathrm{L}^{-1}, \mathrm{pH} 7.0$ ) in an iced mortar, and the solution was then centrifuged at $3820 g_{n}$ for $15 \mathrm{~min}$ at $4{ }^{\circ} \mathrm{C}$. The supernatant was collected as a crude PPO extract. The reaction mixture consisted of $1.0 \mathrm{~mL} 0.1 \mathrm{~mol} \cdot \mathrm{L}^{-1}$ catechol and $1.5 \mathrm{~mL}$ $0.05 \mathrm{~mol} \cdot \mathrm{L}^{-1}$ PBS $(\mathrm{pH} 7.0$ ). Afterward, the mixture was incubated at $35{ }^{\circ} \mathrm{C}$ for $5 \mathrm{~min}, 1.0 \mathrm{~mL}$ crude PPO was added into the previous mixture, and the mixture of changes in the absorbance at $420 \mathrm{~nm}$ was measured. One unit of PPO activity was defined as a change of 0.001 at $420 \mathrm{~nm}$ in absorbance per minute. 
POD ACTIVITy. POD was extracted and assayed spectrophotometrically according to previous work (Min et al., 2017). In a mortar, $5.0 \mathrm{~g}$ fresh-cut lotus root was homogenized with

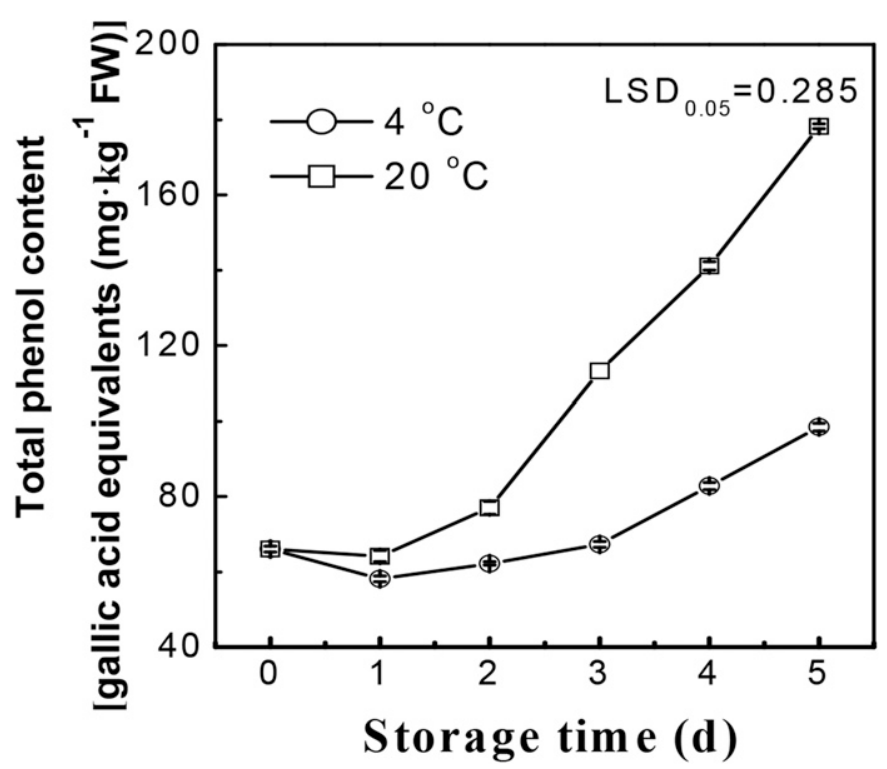

Fig. 2. Effects of two different temperatures on total phenol content of fresh-cut lotus root ('E Lian 5'). Total phenol was the main substrate for enzymatic browning. Fresh-cut lotus root was stored at $4{ }^{\circ} \mathrm{C}$ (circles) and $20{ }^{\circ} \mathrm{C}$ (squares), separately. Error bars represent the SE from three biological replicates. $\mathrm{LSD}=$ least significant difference; $\mathrm{FW}=$ fresh weight.
$5.0 \mathrm{~mL} 0.2 \mathrm{~mol} \cdot \mathrm{L}^{-1} \mathrm{PBS}(\mathrm{pH} 7.0) 1 \mathrm{~mol} \cdot \mathrm{L}^{-1}$ polyethylene glycol, $4 \%(\mathrm{w} / \mathrm{v})$ polyvinyl polypyrrolidone, and $1 \%(\mathrm{w} / \mathrm{v})$ nonionic surfactant (Triton X-100; AMRESCO, Solon, OH) in an ice bath. The homogenates were then centrifuged at 15,290 $g_{\mathrm{n}}$ for $30 \mathrm{~min}$ at $4{ }^{\circ} \mathrm{C}$. The supernatant was collected for the POD activity assay. The reaction cuvette contained $3.0 \mathrm{~mL} 25$ $\mathrm{mmol} \cdot \mathrm{L}^{-1}$ guaiacol, $0.5 \mathrm{~mL}$ enzyme solution (the blank group for PBS), and $0.2 \mathrm{~mL} 5 \mathrm{~mol} \cdot \mathrm{L}^{-1}$ dissolved hydrogen peroxide. The change of the mixture in absorbance at $470 \mathrm{~nm}$ was recorded once every $10 \mathrm{~s}$. An enzyme activity unit was defined spectrophotometrically as an increase of 0.01 at $470 \mathrm{~nm}$ in absorbance per minute per gram fresh weight.

RNA EXTRACTION AND COMPLEMENTARY DNA SYNTHESIS. Total RNA was prepared according to a method used previously (Min et al., 2015). Traces of contaminating genomic DNA in total RNA were removed with TURBO Dnase (Ambion, Austin, TX). A total of $1.0 \mu \mathrm{g}$ DNA-free RNA was used for complementary DNA (cDNA) synthesis using an iScript cDNA Synthesis Kit (Bio-Rad Laboratories, Hercules, CA) following the manufacturer's protocol. For each sampling point, three biological replicates were used for RNA extraction.

GeNe ISOlation AND SEQuenCe ANALYSIS. The $E R F$ genes were isolated based on the RNA-Seq and NCBI databases. RNA-Seq isolation was performed by the Beijing Genome Institute (Shenzhen, China) as reported previously (Min et al., 2014). The sequences of primers used for gene cloning are listed in Table 1. Phylogenetic trees of ERF genes were calculated and generated using FigTree (version 1.3.1; University of Edinburgh, Edinburgh, UK).
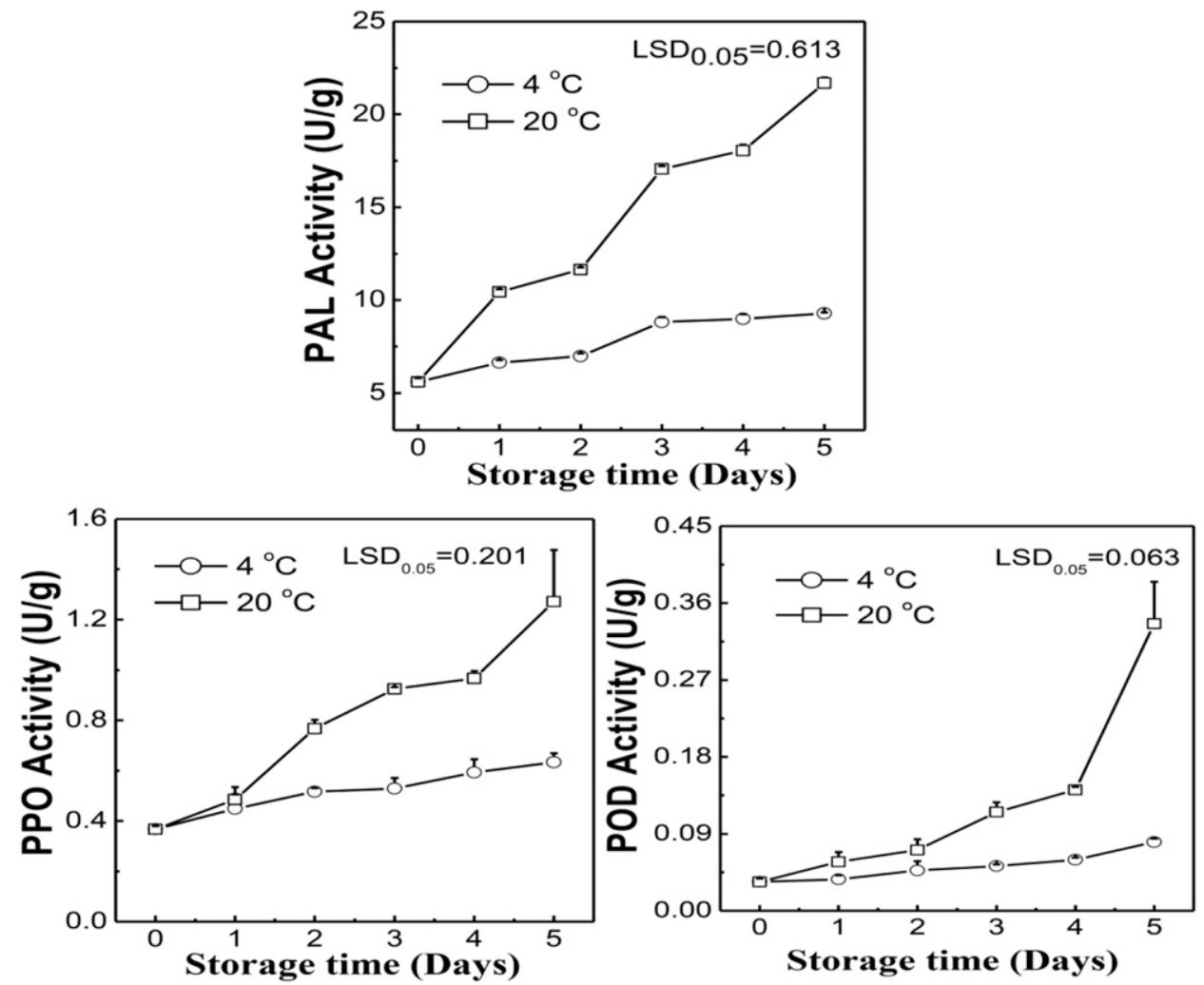

Fig. 3. Effects of two different temperatures on phenylalanine ammonia lyase (PAL), polyphenol oxidase (PPO), and peroxidase (POD) activity of fresh-cut lotus root ('E Lian 5'). PAL, PPO, and POD have been proposed as being involved in enzymatic browning. Fresh-cut lotus root was stored at $4{ }^{\circ} \mathrm{C}$ (circles) and $20{ }^{\circ} \mathrm{C}$ (squares), separately. Error bars represent the SE from three biological replicates. $\mathrm{LSD}=$ least significant difference.
The amino acid sequences of homologous genes of different species were obtained from the NCBI database.

OligonUCleotide PRIMERS AND REAL-TIME POLYMERASE CHAIN REACTION ANALYSIS. Oligonucleotide primers for real-time polymerase chain reaction (PCR) analysis were designed using primer 3 (Min et al., 2017). The specificity of primers was determined by melting curves and PCR product resequencing as described in Min et al. (2012). The sequences of oligonucleotide primers are listed in Table 2. Real-time PCR was carried out with a Ssofast EvaGreen Supermix kit (Bio-Rad Laboratories) and a CFX96 (Bio-Rad Laboratories) optics module for gene expression studies according to our previous reports (Min et al., 2015, 2017).

Statistical analysis. Figures were drawn using Origin 8.0 software (OriginLab, Northhampton, MA). Statistical analysis of differences was analyzed by least significant difference using DPS7.05 software (Zhejiang University, Hangzhou, China). 


\section{Results and Discussion}

Lotus ROOT BROWNING AND TOTAL PHENOL CHANGES. BD remained almost constant during storage at $4{ }^{\circ} \mathrm{C}$, whereas the $20{ }^{\circ} \mathrm{C}$ temperature storage caused a rapid increase in $\mathrm{BD}$ from 0.236 at $0 \mathrm{~d}$ to 1.584 at $5 \mathrm{~d}$ (Fig. 1 ). Phenols increased $\approx 3$-fold in the $20{ }^{\circ} \mathrm{C}$ sample after $5 \mathrm{~d}$ of storage. However, the total phenol content of the samples at $4{ }^{\circ} \mathrm{C}$ showed no obvious change, only a slight increase (Fig. 2).

$\mathrm{BD}$ value was the main index for evaluating browning. By analyzing the change in BD in storage at two different temperatures, these results confirmed our previous results (Min et al., 2017) and those of others (Kang et al., 2012; Kwon and Baek, 2014). Thus, this is further support that lowtemperature storage is effective in delaying the browning of fresh-cut lotus root ('E Lian 5'). When comparing the total phenol content of fresh-cut lotus root ('E Lian 5') in storage at two different temperatures, the value of total phenols was greater at $20{ }^{\circ} \mathrm{C}$, which is consistent with previous reports (Abohatem et al., 2011; Min et al., 2017).

PAL, PPO, AND POD ACTIVITy Changes. The effects of the two different temperatures on PAL, PPO, and POD activity clearly differed during storage (Fig. 3). PAL activity of the samples at the two different temperatures showed varying

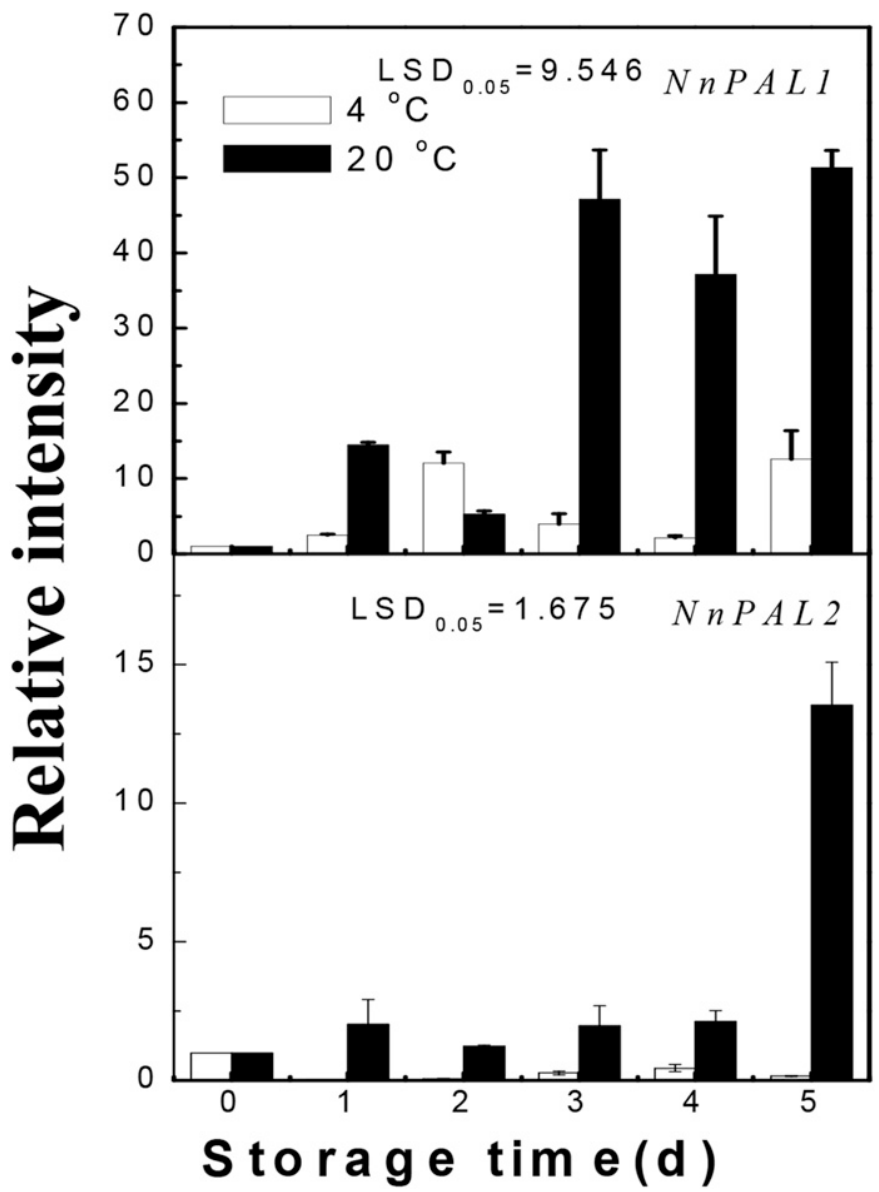

Fig. 4. Messenger RNA amounts from phenylalanine ammonia lyase $(P A L)$ genes in response to different temperature treatments. Fresh-cut lotus root was stored at $4{ }^{\circ} \mathrm{C}$ (white) and $20^{\circ} \mathrm{C}$ (black), separately. Zero-day sample values were set at 1 . Error bars represent the SE from three biological replicates. $\mathrm{LSD}=$ least significant difference. degrees of increase, from an initial value of 5.594 to $9.284 \mathrm{U} / \mathrm{g}$ $\left(4{ }^{\circ} \mathrm{C}\right)$ and $21.683 \mathrm{U} / \mathrm{g}\left(20^{\circ} \mathrm{C}\right)$ in $5 \mathrm{~d}$. The PPO activity of the samples at $4{ }^{\circ} \mathrm{C}$ showed a slow increase from an initial value of 0.367 to $0.633 \mathrm{U} / \mathrm{g}$ in $5 \mathrm{~d}$. However, PPO activity increased rapidly at $20{ }^{\circ} \mathrm{C}$ from an initial value of 0.367 to $1.271 \mathrm{U} / \mathrm{g}$ in $5 \mathrm{~d}$. POD activity of the samples at $4{ }^{\circ} \mathrm{C}$ showed a slow increase, from an initial value of 0.034 to $0.080 \mathrm{U} / \mathrm{g}$ in $5 \mathrm{~d}$. However, POD activity increased rapidly at $20^{\circ} \mathrm{C}$ from an initial value of 0.034 to $0.336 \mathrm{U} / \mathrm{g}$ in $5 \mathrm{~d}$.

As mentioned previously, PAL, PPO, and POD have been proposed to be involved in enzymatic browning in lotus root (Hu et al., 2014; Min et al., 2017; Zhang et al., 2013). By analyzing the change in PAL, PPO, and POD enzymatic activity in storage at two different temperatures, it is clear that the greater the temperature, the faster the increase in PAL, PPO, and POD activity, which was in agreement with previous results (Min et al., 2017).

PAL, PPO, AND POD GENe EXPREsSion. There was a strong differential response to temperature for two $P A L$, two $P P O$, and seven $P O D$ genes. Expression of $N n P A L 1$ was particularly responsive to the $20-{ }^{\circ} \mathrm{C}$ temperature induced from $0 \mathrm{~d}$, reaching a peak at $3 \mathrm{~d}$ and maintaining a high level thereafter. NnPAL2 expression increased gradually during storage and peaked at $5 \mathrm{~d}$ (Fig. 4). The influence of temperature on the expression of the two PPO genes was similar to the PAL genes (Fig. 5), being

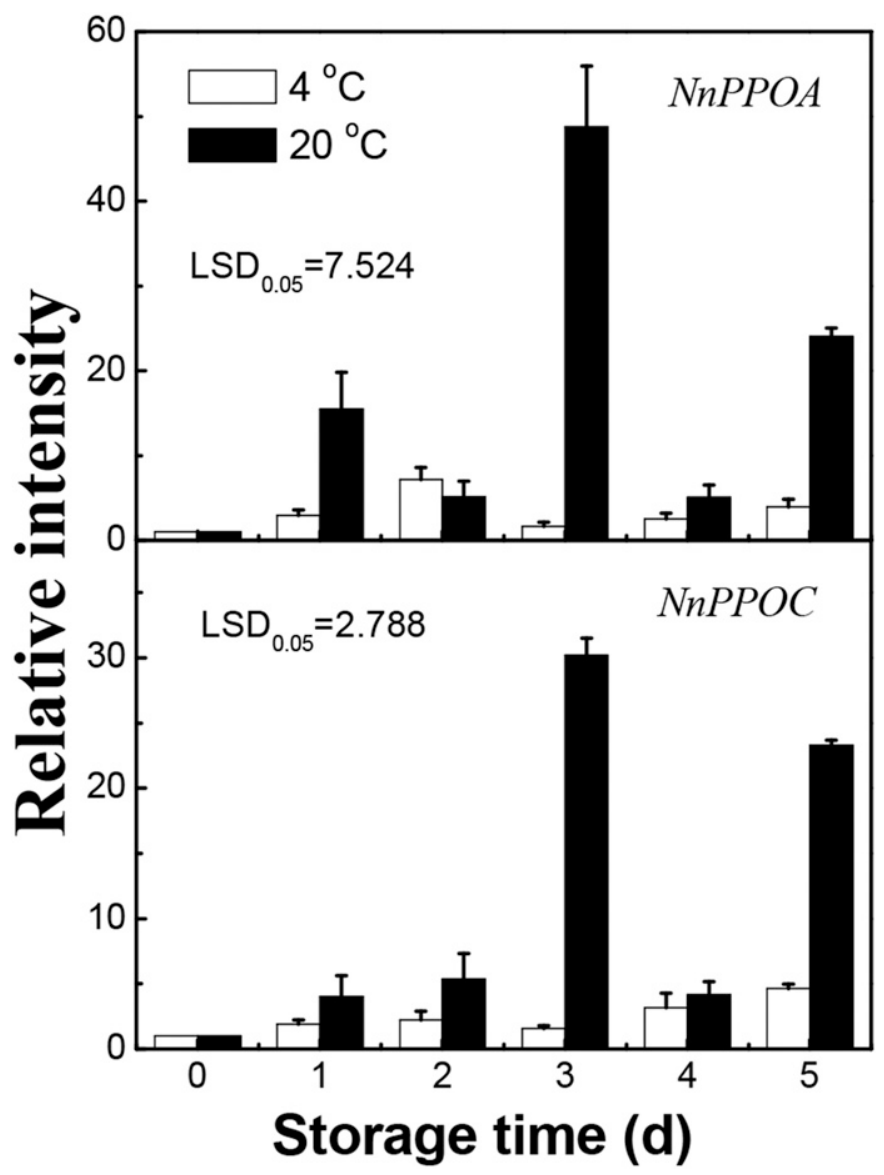

Fig. 5. Messenger RNA amounts from polyphenol oxidase (PPO) genes in response to different temperature treatments. Fresh-cut lotus root was stored at $4{ }^{\circ} \mathrm{C}$ (white) and $20{ }^{\circ} \mathrm{C}$ (black), separately. Error bars represent the sE from three biological replicates. $\mathrm{LSD}=$ least significant difference. 


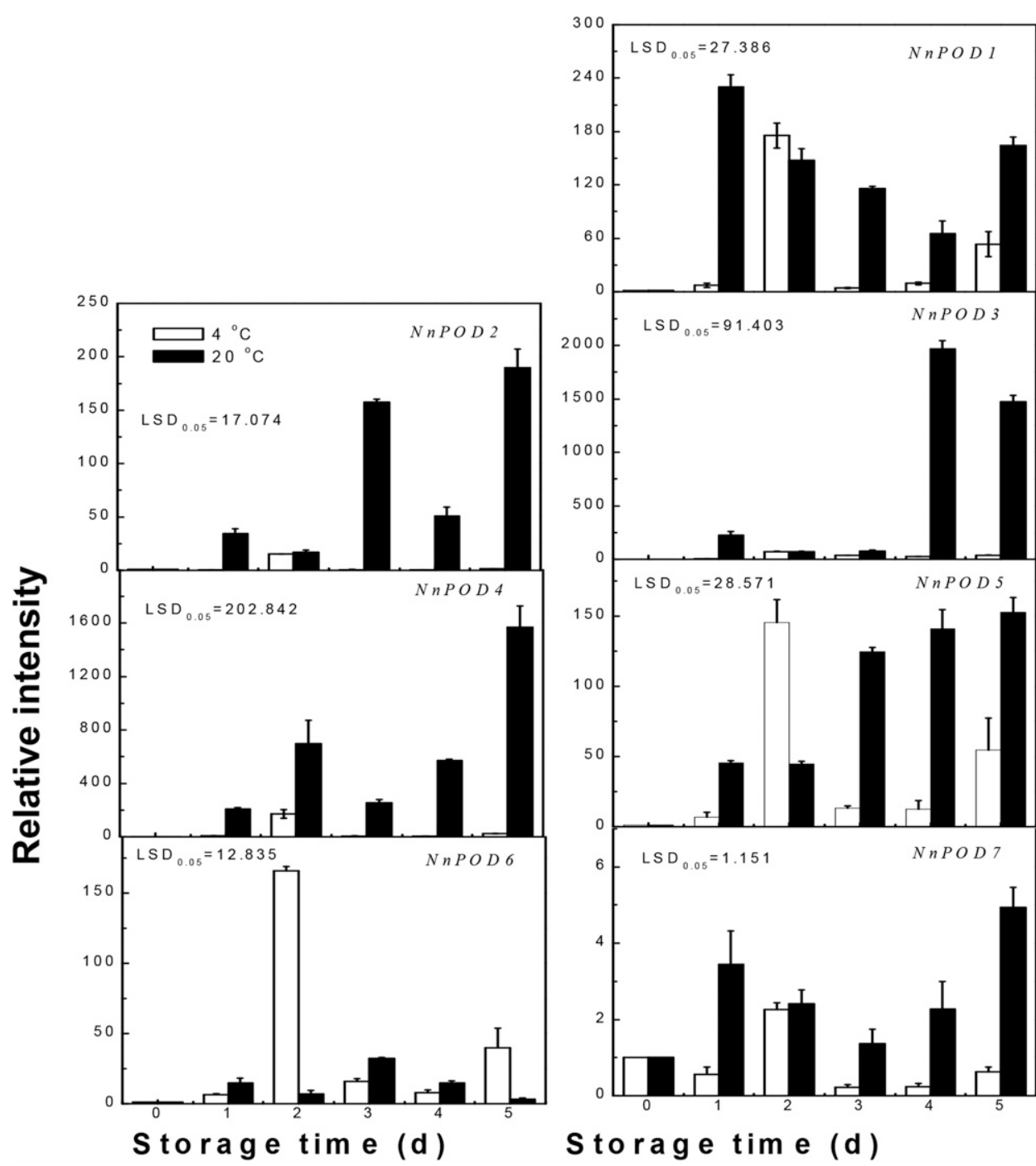

Fig. 6. Messenger RNA amounts from peroxidase $(P O D)$ genes in response to different temperature treatments. Fresh-cut lotus root was stored at $4{ }^{\circ} \mathrm{C}$ (white) and $20{ }^{\circ} \mathrm{C}$ (black), separately. Error bars represent the SE from three biological replicates. $\mathrm{LSD}=$ least significant difference.

induced at $20^{\circ} \mathrm{C}$ and reaching a peak at $3 \mathrm{~d}$. The seven $P O D$ genes exhibited different expression patterns. Transcripts of NnPOD2, NnPOD3, and NnPOD4 were induced continuously by a $20{ }^{\circ} \mathrm{C}$ temperature and peaked on $5 \mathrm{~d}$, with messenger RNA (mRNA) increasing in abundance $\approx 200-, 1400-$, and 1500 -fold after storage at $20{ }^{\circ} \mathrm{C}$, respectively. NnPOD1, NnPOD5, and NnPOD7 were induced to varying degrees by the two different temperatures during storage, albeit in varying degrees. Unlike the other $N n P O D$ genes, the expression of $N n P O D 6$ was increased with storage at $4{ }^{\circ} \mathrm{C}$ (Fig. 6).

Two $N n P A L$, two $N n P P O$, and seven $N n P O D$ genes were isolated in our earlier work (Min et al., 2017). In this study, $N n P A L 1 / 2, N n P P O A / \mathrm{C}$, and NnPOD2-4 were substantially more responsive to high temperature than the other gene family members. However, the genes used in the current study were somewhat different from our previous work (Min et al., 2017), in which we found that the upregulation of $N n P A L 1, N n P P O A$, and $N n P O D 1-6$ at high temperatures coincided with an increase in fresh-cut lotus root $\mathrm{BD}$, which may be because of the differences in raw materials. Considering our previous study and our current results, NnPAL1, NnPPOA, and NnPOD2-5 should be considered important candidates for fresh-cut lotus root browning, and further functional analysis needs to be performed.

ERF GENE ISOLATION AND PHYLOGENETIC ANALYSIS. Seven $E R F$ cDNAs (NnERF1-XM_010280223.1, NnERF2-XM_010276487.1, NnERF3-XM_010252213, NnERF4XM_010263237.1, NnERF5XM_010264002.1, NnERF6XM_010247968.1, and NnERF7XM_010243726.1) were cloned from RNA collected from lotus root (' $\mathrm{E}$ Lian 5') using the RNA-Seq and NCBI databases, all of which were partial coding sequences. These were aligned with the Arabidopsis thaliana ERF family. The amino acid sequences were obtained from the Arabidopsis Information Resource and NCBI databases. The subfamily name was based on a previous report (Nakano et al., 2006).

Phylogenetic analysis of the amino acid sequences showed that $N n E R F$ coding sequences could be divided into different groups (Fig. 7). NnERF1 belongs to the subfamily III group; the $E R F$ genes in this type have been reported to play an important role in cold response (Klay et al., 2014). NnERF2 is closely related to subfamily VIII; the $E R F$ genes in this type have been reported to play an important role in ethylene response and plant development (Pirrello et al., 2012). $N n E R F 3$ is similar to subfamily $\mathrm{V}$; the $E R F$ genes in this type have been reported to play an important role in ethylene and jasmonic acid response (Asahina et al., 2011). NnERF4 and NnERF6 in one group are similar to subfamily I; the $E R F$ genes in this type have been reported to play an important role in abiotic responses, including cold and heat tolerance (Figueroa-Yañez et al., 2016). $N n E R F 5$ is similar to subfamily IX; the ERF genes in this type have been reported to play an important role in regulating the plant defense response (Oñate-Sánchez et al., 2007). NnERF7 is similar to subfamily II; the $E R F$ genes in this type have been reported to be negative transcriptional regulators in defense responses to cold and drought stress in arabidopsis (Dong and Liu, 2010).

ERF GENE EXPRESSION. The seven $E R F$ genes exhibited different expression patterns (Fig. 8). Transcripts of NnERF3/4/ 5 were reduced continuously by the low temperature $\left(4^{\circ} \mathrm{C}\right)$. The expression of $N n E R F 3$ peaked after $3 \mathrm{~d}$, and $N n E R F 5$ was the most strongly upregulated at $20^{\circ} \mathrm{C}$ compared with at $4{ }^{\circ} \mathrm{C}$, with its mRNA increasing in abundance $\approx 150$-fold after storage. The downregulation by low temperature $\left(4^{\circ} \mathrm{C}\right)$ of $N n E R F 3 / 4 / 5$ is similar to the response of $E R F$ genes in other plants, such as arabidopsis (Lim et al., 2007), Cicer arietinum, 


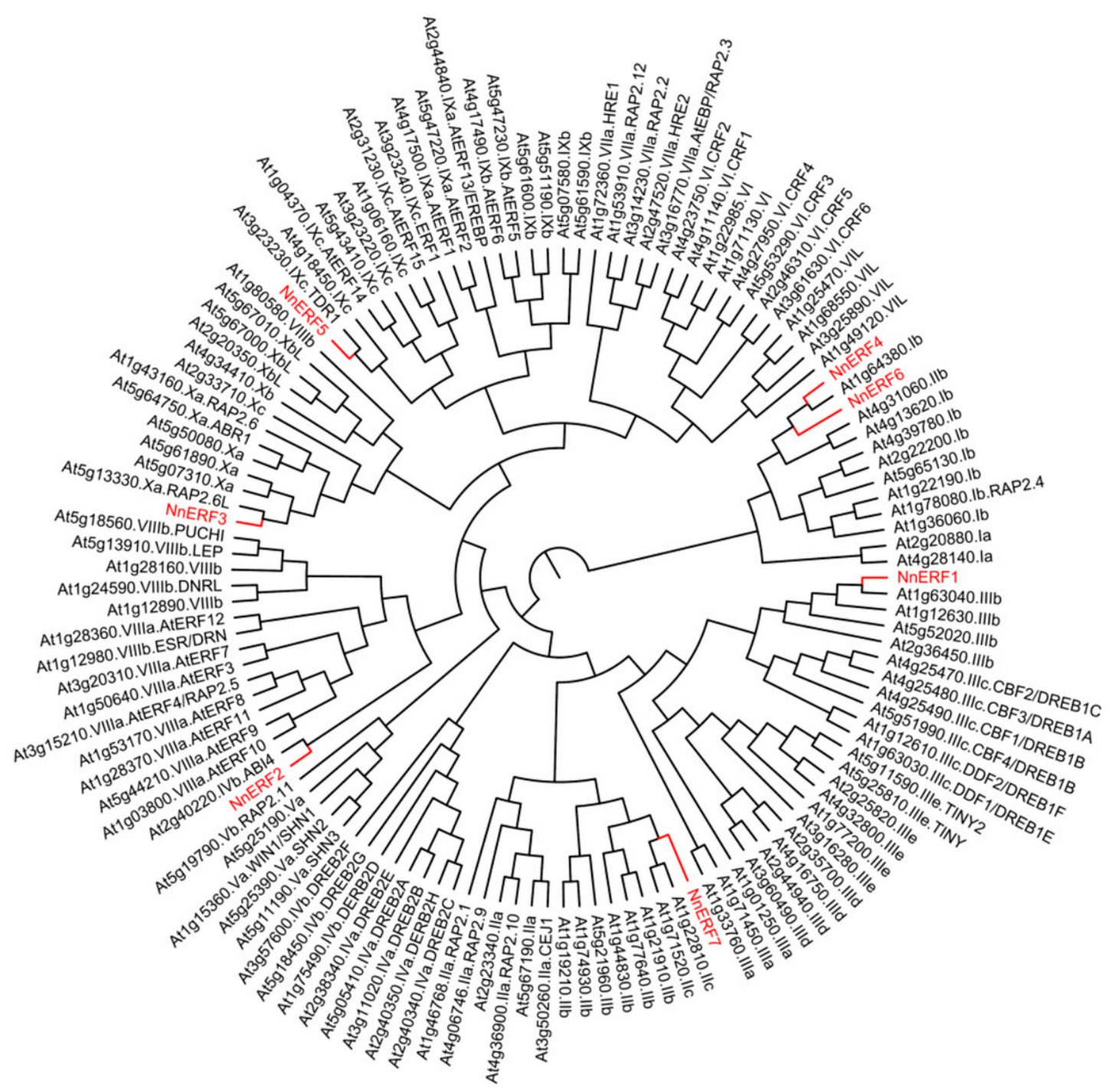

Fig. 7. Phylogenetic tree of ethylene response factor $(E R F)$ genes. Lotus root $N n E R F$ genes are highlighted in red. The amino acid sequences of the Arabidopsis ERF family were obtained from The Arabidopsis Information Resource (TAIR).

and Cajanus cajan (Agarwal et al., 2016). In contrast, transcripts of $N n E R F 1 / 2 / 7$ increased at the low temperature $\left(4{ }^{\circ} \mathrm{C}\right)$. Unlike the other NnERF genes, the expression of NnERF6 showed no clear difference between the different temperatures (Fig. 8).

One of most interesting results is that $N n E R F 3 / 4 / 5$ were downregulated at the low temperature $\left(4^{\circ} \mathrm{C}\right)$, and this occurred concomitantly with the decrease in NnPAL1, NnPPOA, and $N n P O D 2 / 3 / 4 / 5$ gene expression and BD. This indicates that, in lotus root, the increased expression of $N n E R F 3 / 4 / 5$ was concurrent with an increase in browning, although the specific relationship between $E R F$ and browning is unclear (and should be studied further).

The expression pattern of NnERF4 further supports the prediction of phylogenetic analyses that the $E R F$ genes in subfamily I have been reported to play an important role in cold and heat tolerance (Figueroa-Yañez et al., 2016). In addition, $N n E R F 3$ and NnERF5 were also observed to decrease expression in response to the low temperature $\left(4^{\circ} \mathrm{C}\right)$. However, NnERF3 and NnERF5 belong to subfamilies V and IX, respectively. Taken together, these results may indicate that more subfamilies could be involved in the cold and heat response to browning in lotus root.

In addition to the three previously mentioned $N n E R F$ genes, $N n E R F 1 / 2 / 7$ expression also exhibited interesting features. Unlike the positively regulated $E R F$ genes, NnERF1/2/7 mRNA levels were associated negatively with browning, which was upregulated by the low temperature $\left(4{ }^{\circ} \mathrm{C}\right)$ in storage. It is well known that the processing of fresh-cut fruits and vegetables promotes faster physiological deterioration, biochemical change, and microbial degradation of the product, which may result in degradation of the color, texture, and flavor (Toivonen and Brummell, 2008). These results indicate that NnERF1/2/7 might be involved in senescence-related or corruption processes for fruits and vegetables, but not browning. Similar results have also been reported for other fruits, such as Actinidia sinensis, in which AdERF9 and EILs suppress the promoter activity of ripening-related genes and regulate fruitripening and -softening processes (Yin et al., 2010). It has also been reported that GmERF113, a novel glycine max ERF transcription factor, may play a crucial role in the defense against Phytophthora sojae infection (Zhao et al., 2017). 


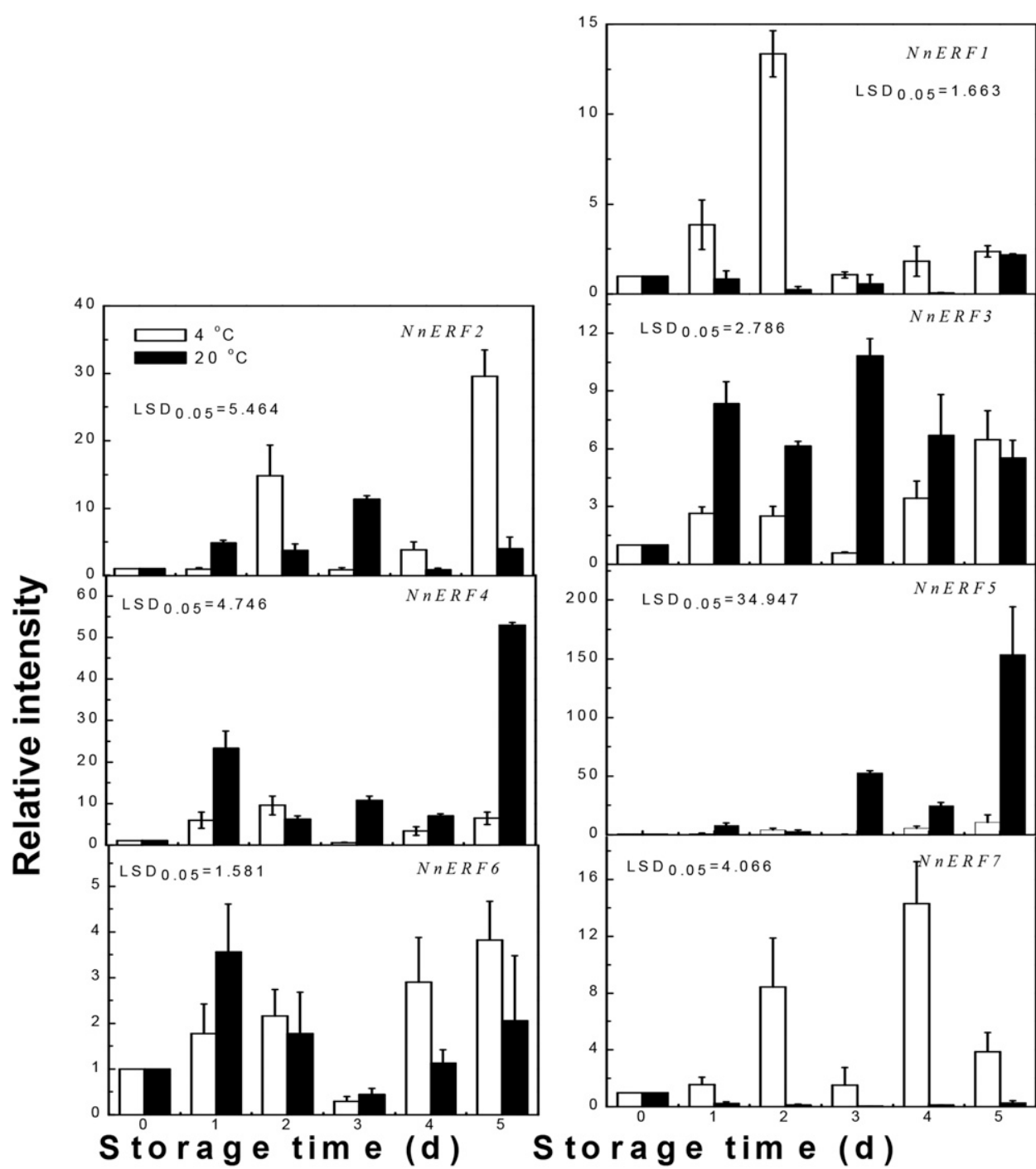

Fig. 8. Messenger RNA amounts from ethylene response factor $(E R F)$ genes in response to different temperature treatments. Fresh-cut lotus root was stored at $4{ }^{\circ} \mathrm{C}$ (white) and $20{ }^{\circ} \mathrm{C}$ (black), separately. Error bars represent the SE from three biological replicates. $\mathrm{LSD}=$ least significant difference.

\section{Conclusions}

The degree of browning; PAL, PPO, and POD enzyme activity; and gene expression assay results in the current study showed that storage at a low temperature is effective in delaying lotus root browning. Seven $N n E R F$ genes were isolated and the transcriptional levels of $N n E R F 3 / 4 / 5$ were associated with fresh-cut lotus root browning. NnERF3/4/5 are prime candidates for additional transcriptional regulatory analysis in lotus root to understand the molecular control of browning.

\section{Literature Cited}

Abohatem, M., J. Zouine, and I. El Hadrami. 2011. Low concentrations of BAP and high rate of subcultures improve the establishment and multiplication of somatic embryos in date palm suspension cultures by limiting oxidative browning associated with high levels of total phenols and peroxidase activities. Scientia Hort. 130:344-348.

Agarwal, G., V. Garg, H. Kudapa, D. Doddamani, L.T. Pazhamala, A.W. Khan, M. Thudi, S.H. Lee, and R.K. Varshney. 2016. Genome-wide dissection of AP2/ERF and HSP90 gene families in five legumes and expression profiles in chickpea and pigeonpea. Plant Biol. J. 14:1563-1577.

Asahina, M., K. Azuma, W. Pitaksaringkarn, T. Yamazaki, N. Mitsuda, M. OhmeTakagi, S. Yamaguch, Y. Kamiya, K. Okada, and T. Nishimura. 2011. Spatially selective hormonal control of RAP2.6L and ANAC071 transcription factors involved in tissue reunion in arabidopsis. Proc. Natl. Acad. Sci. USA 108:16128-16132.

Banerjee, A., S. Penna, P.S. Variyar, and A. Sharma. 2015. Gamma irradiation inhibits wound induced browning in shredded cabbage. Food Chem. 173:38-41.

Cheng, L., L. Hui, L. Yin, S.Y. Li, X.H. Chen, and L.J. Li. 2015a. Overexpression of NnDREB2 isolated from lotus improves salt tolerance in transgenic Arabidopsis thaliana. Acta Physiol. Plant. 37:1-12.

Cheng, Y.D., L.Q. Liu, G.Q. Zhao, C.G. Shen, H.B. Yan, J.F. Guan, and K. Yang. 2015b. The effects of modified atmosphere packaging on core browning and the expression patterns of PPO and PAL genes in 'Yali' pears during cold storage. Lebensm. Wiss. Technol. 60:1243-1254.

Conesa, A., B.E. Verlinden, F. ArtesHernandez, B. Nicolai, and F. Artes. 2007. Respiration rates of fresh-cut bell peppers under superatmospheric and low oxygen with or without high carbon dioxide. Postharvest Biol. Technol. 45:81-88.

Dong, C.J. and J.Y. Liu. 2010. The Arabidopsis EAR-motif-containing protein RAP2.1 functions as an active transcriptional repressor to keep stress responses under tight control. BMC Plant Biol. 10:47.

Figueroa-Yañez, L., A. Pereira-Santana, A. Arroyo-Herrera, U. Rodriguez-Corona, F. Sanchez-Teyer, J. Espadas-Alcocer, F. Espadas-Gil, F. Barredo-Pool, E. Castano, and L.C. Rodriguez-Zapata. 2016. RAP2.4a is transported through the phloem to regulate cold and heat tolerance in papaya tree (Carica papaya $\mathrm{cv}$. Maradol): Implications for protection against abiotic stress. PLoS One 11: e0165030.

Francis, G.A., A. Gallone, G.J. Nychas, J.N. Sofos, G. Colelli, M.L. Amodio, and G. Spano. 2012. Factors affecting quality and safety of fresh-cut produce. Crit. Rev. Food Sci. Nutr. 52:595-610.

Guo, H., Y. Sun, Y. Li, X.H. Liu, W.H. Zhang, and F. Ge. 2014. Elevated $\mathrm{CO}_{2}$ decreases the response of the ethylene signaling pathway in Medicago truncatula and increases the abundance of the pea aphid. New Phytol. 201:279-291.

He, J., Q. Zhu, X. Dong, H.Y. Pan, J. Chen, and Z.P. Zheng. 2017. Oxyresveratrol and ascorbic acid O/W microemulsion: Preparation, characterization, anti-isomerization and potential application as antibrowning agent on fresh-cut lotus root slices. Food Chem. 214:269-276.

Hodges, D.M. and P.M.A. Toivonen. 2008. Quality of fresh-cut fruits and vegetables as affected by exposure to abiotic stress. Postharvest Biol. Technol. 48:155-162.

Hu, J.Q., L.Z. Yang, W.J. Wu, Y. Li, and L.J. Zhan. 2014. Slicing increases antioxidant capacity of fresh-cut lotus root (Nelumbo 
nucifera G.) slices by accumulating total phenols. Intl. J. Food Sci. Technol. 49:2418-2424.

Kang, Y.Y., X.J. Liu, X. Yang, and A.Z. Huang. 2012. Effects of storage temperature on quality and preservation of lotus roots. Guangdong Agr. Sci 15:84-85, 93.

Karlova, R.L., F.M. Rosin, J. Busscher-Lange, V. Parapunova, P.T. Do, A.R. Fernie, P.D. Fraser, C. Baxter, G.C. Angenent, and R.A. de Maagd. 2011. Transcriptome and metabolite profiling show that APETALA2a is a major regulator of tomato fruit ripening. Plant Cell 23:923-941.

Kimura, S., Y. Chikagawa, M. Kato, K. Maeda, and Y. Ozeki. 2008. Upregulation of the promoter activity of the carrot (Daucus carota) phenylalanine ammonia-lyase gene (DcPAL3) is caused by new members of the transcriptional regulatory proteins, DcERF1 and DcERF2, which bind to the GCC-box homolog and act as an activator to the DcPAL3 promoter. J. Plant Res. 121:499.

Klay, I., J. Pirrello, L. Riahi, A. Bernadac, A. Cherif, M. Bouzayen, and S. Bouzid. 2014. Ethylene response factor S1-ERF.B.3 is responsive to abiotic stresses and mediates salt and cold stress response regulation in tomato. Sci. World J. 2014:167681.

Kwon, S.Y. and H.H. Baek. 2014. Effects of temperature, pH, organic acids, and sulfites on tagatose browning in solutions during processing and storage. Food Sci. Biol. 23:677-684.

Li, L., T. Kaplunov, Y. Zutahy, A. Daus, R. Porat, and A. Lichter. 2015. The effects of 1-methylcyclopropane and ethylene on postharvest rachis browning in table grapes. Postharvest Biol. Technol. 107:16-22.

Licausi, F., M. Ohme-Takagi, and P. Perata. 2013. APETALA2/ ethylene responsive factor (AP2/ERF) transcription factors: Mediators of stress responses and developmental programs. New Phytol. 199:639-649.

Lim, C.J., J.E. Hwang, H. Chen, J.K. Hong, K.A. Yang, M.S. Choi, K.O. Lee, W.S. Chung, S.Y. Lee, and C.O. Lim. 2007. Over-expression of the Arabidopsis DRE/CRT-binding transcription factor DREB2C enhances thermotolerance. Biochem. Biophys. Res. Commun. 362:431-436.

Min, T., F. Fang, H. Ge, Y.N. Shi, Z.R. Luo, Y.C. Yao, D. Grierson, X.R. Yin, and K.S. Chen. 2014. Two novel anoxia-induced ethylene response factors that interact with promoters of deastringencyrelated genes from persimmon. PLoS One 9:e97043.

Min, T., J. Xie, M.L. Zheng, Y. Yi, W.F. Hou, L.M. Wang, Y.W. Ai, and H.X. Wang. 2017. The effect of different temperatures on browning incidence and phenol compound metabolism in fresh-cut lotus (Nelumbo nucifera, G.) root. Postharvest Biol. Technol. 123:69-76.

Min, T., M.M. Wang, H.X. Wang, X.F. Liu, F. Fang, D. Grierson, X.R. Yin, and K.S. Chen. 2015. Isolation and expression of NAC genes during persimmon fruit postharvest astringency removal. Intl. J. Mol. Sci. 16:1894-1906.

Min, T., X.R. Yin, Y.N. Shi, Z.R. Luo, Y.C. Yao, D. Grierson, I.B. Ferguson, and K.S. Chen. 2012. Ethylene-responsive transcription factors interact with promoters of $\mathrm{ADH}$ and PDC involved in persimmon (Diospyros kaki) fruit de-astringency. J. Expt. Bot. 63:6393-6405.

Mizoi, J., K. Shinozaki, and K. Yamaguchi-Shinozaki. 2012. AP2/ERF family transcription factors in plant abiotic stress responses. Biochim. Biophys. Acta 1819:86-96.
Müller, M. and S. Munné-Bosch. 2015. Ethylene response factors: Key regulatory hub in hormone and stress signaling. Plant Physiol. 169:32-41.

Nakano, T., K. Suzuki, T. Fujimura, and H. Shinshi. 2006. Genomewide analysis of the ERF gene family in arabidopsis and rice. Plant Physiol. 140:411-432.

Oñate-Sánchez, L., J.P. Anderson, J. Young, and K.B. Singh. 2007. AtERF14, a member of the ERF family of transcription factors, plays a nonredundant role in plant defense. Plant Physiol. 143:400-409.

Phukan, U.J., G.S. Jeena, V. Tripathi, and R.K. Shukla. 2017. Regulation of Apetala2/ethylene response factors in plants. Front. Plant Sci. 8:150.

Pirrello, J., B.C. Prasad, W. Zhang, K.S. Chen, L. Mila, M. Zouine, A. Latche, J.C. Pech, M. Ohme-Takagi, and F. Regad. 2012. Functional analysis and binding affinity of tomato ethylene response factors provide insight on the molecular bases of plant differential responses to ethylene. BMC Plant Biol. 12:1-15.

Sun, Y., W. Zhang, T. Zeng, Q.X. Nie, F.Y. Zhang, and L.Q. Zhu. 2015. Hydrogen sulfide inhibits enzymatic browning of fresh-cut lotus root slices by regulating phenolic metabolism. Food Chem. 177:376-381.

Tan, Y.T. and K.F. Zeng. 2014. Effects of combined treatment with ascorbic acid, cysteine and cacl 2 on browning of fresh-cut taro. Food Sci. 4:231-235.

Toivonen, P.M.A. and D.A. Brummell. 2008. Biochemical bases of appearance and texture changes in fresh-cut fruit and vegetables. Postharvest Biol. Technol. 48:1-14.

Wu, Z.J., X.H. Li, Z.W. Liu, H. Li, Y.X. Wang, and J. Zhuang. 2015. Transcriptome-based discovery of AP2/ERF transcription factors related to temperature stress in tea plant (Camellia sinensis). Funct. Integr. Genomics 15:741-752.

Xu, Z.S., M. Chen, L.C. Li, and Y.Z. Ma. 2011. Functions and application of the AP2/ERF transcription factor family in crop improvement. J. Integr. Plant Biol. 53:570-585.

Yin, X.R., A.C. Allan, K.S. Chen, and I.B. Ferguson. 2010. Kiwifruit EIL and ERF genes involved in regulating fruit ripening. Plant Physiol. 153:1280-1292.

Zhang, Z. and R. Huang. 2010. Enhanced tolerance to freezing in tobacco and tomato overexpressing transcription factor TERF2/ LeERF2 is modulated by ethylene biosynthesis. Plant Mol. Biol. 73:241-249.

Zhang, S.Y., Y.W. Yu, C.L. Xiao, X.D. Wang, and Y.Y. Tian. 2013. Effect of carbon monoxide on browning of fresh-cut lotus root slice in relation to phenolic metabolism. Lebensm. Wiss. Technol. 53:555-559.

Zhao, Y., X. Chang, D. Qi, L. Dong, G. Wang, S. Fan, L. Jiang, Q. Cheng, X. Chen, D. Han, P. Xu, and S. Zhang. 2017. A novel soybean ERF transcription factor, GmERF113, increases resistance to Phytophthora sojae infection in soybean. Front. Plant Sci. 8:299.

Zheng, J.L., L.Y. Hu, K.D. Hu, J. Wu, F. Yang, and H. Zhang. 2016. Hydrogen sulfide alleviates senescence of fresh-cut apple by regulating antioxidant defense system and senescence-related gene expression. HortScience 51:152-158.

Zhou, Y.C., J.M. Dahler, S.J.R. Underhill, and R.B.H. Wills. 2003. Enzymes associated with blackheart development in pineapple fruit. Food Chem. 80:565-572. 
Supplemental Table 1. Information for all the ethylene response factors $(E R F \mathrm{~s})$ from the RNA-seq and National Center for Biotechnology Information database.

\begin{tabular}{|c|c|c|}
\hline Gene ID & RPKM at $20^{\circ} \mathrm{C}$ & RPKM at $4{ }^{\circ} \mathrm{C}$ \\
\hline 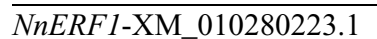 & 31.31653549 & 2.035658 \\
\hline NnERF2-XM_010276487.1 & 1.109555535 & - \\
\hline NnERF3-XM_010252213 & 241.4901856 & 21.80209 \\
\hline NnERF4-XM_010263237.1 & 25.85743426 & 1.369193 \\
\hline NnERF5-XM_010264002.1 & 54.3935825 & 1.393153 \\
\hline NnERF6-XM_010247968.1 & 10.16833966 & - \\
\hline NnERF7-XM_010243726.1 & 0.423318324 & - \\
\hline \multicolumn{3}{|l|}{$X M \_010265290.1$} \\
\hline \multicolumn{3}{|l|}{$X M \_010247014.1$} \\
\hline \multicolumn{3}{|l|}{ XM_010264001.1 } \\
\hline \multicolumn{3}{|l|}{ XM_010266949.1 } \\
\hline \multicolumn{3}{|l|}{ XM_010265165.1 } \\
\hline \multicolumn{3}{|l|}{$X M \_010243704.1$} \\
\hline \multicolumn{3}{|l|}{$X M \_010272292.1$} \\
\hline \multicolumn{3}{|l|}{ XM_010274498.1 } \\
\hline \multicolumn{3}{|l|}{$X M \_010260532.1$} \\
\hline \multicolumn{3}{|l|}{ XM_010247969.1 } \\
\hline \multicolumn{3}{|l|}{ XM_010262090.1 } \\
\hline \multicolumn{3}{|l|}{ XM_010263926.1 } \\
\hline \multicolumn{3}{|l|}{$X M \_010276018.1$} \\
\hline \multicolumn{3}{|l|}{$X M \_010267377.1$} \\
\hline \multicolumn{3}{|l|}{$X M \_010247418.1$} \\
\hline \multicolumn{3}{|l|}{$X M \_010247244.1$} \\
\hline \multicolumn{3}{|l|}{ XM_010265251.1 } \\
\hline \multicolumn{3}{|l|}{$X M \_010254050.1$} \\
\hline \multicolumn{3}{|l|}{ XM_010264640.1 } \\
\hline \multicolumn{3}{|l|}{$X M \_010267180.1$} \\
\hline \multicolumn{3}{|l|}{ XM_010263467.1 } \\
\hline \multicolumn{3}{|l|}{ XM_010271692.1 } \\
\hline \multicolumn{3}{|l|}{ XM_010277121.1 } \\
\hline \multicolumn{3}{|l|}{$X M \_010266854.1$} \\
\hline \multicolumn{3}{|l|}{$X M \_010276486.1$} \\
\hline \multicolumn{3}{|l|}{ XM_010260875.1 } \\
\hline \multicolumn{3}{|l|}{$X M \_010267406.1$} \\
\hline \multicolumn{3}{|l|}{ XM_010266127.1 } \\
\hline$X M \_010246498.1$ & & \\
\hline XM_010266126.1 & & \\
\hline XM_010268255.1 & & \\
\hline
\end{tabular}

$\mathrm{RPKM}=$ reads per kilobase per million reads. 